\title{
Prevention of Clinical Mastitis with Barium Selenate in Dairy Goats from a Selenium-Deficient Area
}

\author{
J. Sánchez, ${ }^{1}$ P. Montes, A. Jiménez, and S. Andrés \\ Animal Health and Medicine Department, Faculty of Veterinary Sciences, 10071 Cáceres, Spain
}

\begin{abstract}
Mastitis is one of the most negative factors involved in the economy of dairy goat farms. The effect of selenium on mammary gland resistance to infectious diseases has been demonstrated. This work evaluates the efficacy of a slow-release Se salt (barium selenate) to reduce the incidence of clinical mastitis in goats reared on Se-deficient areas. Six hundred milking goats of the Malagueña breed, from 4 commercial dairy farms located in a Se-deficient area, were randomly allotted to 2 groups: treated group (given a subcutaneous injection of barium selenate at a dose of $1 \mathrm{mg}$ of Se/kg of body weight $15 \mathrm{~d}$ before mating) and control group (no supplement). During the lactation the does were monitored to assess the occurrence of clinical mastitis by physical examination, California Mastitis Test performance, and microbiological study. The Se content of the ration consumed previously by the animals did not meet the requirements for dairy goats. The Se injection significantly increased glutathione peroxidase activity in the treated group and had evident beneficial effects in the subsequent lactation. The somatic cell count and the incidence of clinical mastitis were significantly lower in the treated group than in the control group. However, no significant differences were found for milk composition. Thus, in Se-deficient areas, the supplementation with Se of any source in programs for prevention of clinical mastitis and improvement of milk quality is strongly recommended.
\end{abstract}

Key words: selenium, clinical mastitis, dairy goat, somatic cell count

\section{INTRODUCTION}

Mastitis is an inflammation of the mammary gland, regardless of cause, characterized by physiological, chemical, and bacteriological changes in milk and by pathological changes in glandular tissue (Matthews,

Received September 21, 2006.

Accepted December 13, 2006.

${ }^{1}$ Corresponding author: peinado@unex.es
1999). The condition is one of the most negative factors involved in the economy of dairy goat farms. Its economic impact is primarily a result of the clinical nature of the disease. The majority of these expenses are due to lost production, discarded milk following therapy, and veterinary costs (Contreras et al., 1997). Mastitis control programs include therapy in the dry period, treatment of clinical mastitis cases, culling, proper maintenance of the milking equipment, and well-balanced rations (Smith et al., 1997).

Selenium is an essential micronutrient present in tissues throughout the body; it is important physiologically because it is an integral component of the enzyme glutathione peroxidase (GSHpx; Miller et al., 1993). Glutathione peroxidase functions in the cytosol of the cell; it protects polymorphonuclear neutrophils against reactive oxygen species production, increases survival of leukocytes involved in cellular defense, and improves the activity of these cells in the mammary gland (Hogan et al., 1989; Smith et al., 1997).

The effect of Se on mammary gland resistance to infectious diseases has been demonstrated in cows by an enhancement of the function of mammary phagocytes (Smith et al., 1997) and inhibition of the growth of pathogens in milk (Malbe et al., 2006). A negative correlation between percentage of quarters infected with major pathogens and mean herd GSHpx activity in whole blood has been recorded (Erskine et al., 1987), and Atroshi et al. (1985) reported that mastitic dairy goats had lower erythrocyte GSHpx than healthy goats. Thus, it may be presumed that Se deficiency could represent a predisposing factor to mastitis (Morgante et al., 1999).

The aim of this work was to evaluate the efficacy of a slow-release Se salt (barium selenate) to reduce the incidence of clinical mastitis in goats reared on Sedeficient areas, when production is linked to grazing and the supply of food from other areas is limited.

\section{MATERIALS AND METHODS}

\section{Does}

Four commercial dairy goat farms of the Malagueña breed participated in this study. This dairy breed is 
Table 1. Number of lactating goats in both groups of each farm and in total in the beginning of the experiment

\begin{tabular}{lccc}
\hline Farm & $\mathrm{n}$ & Treated & Control \\
\hline AT & 120 & 60 & 60 \\
EC & 150 & 75 & 75 \\
PM & 120 & 60 & 60 \\
SA & 130 & 65 & 65 \\
Total & 520 & 260 & 260 \\
\hline
\end{tabular}

widespread over southern Spain and North Africa. The trial was conducted in the region of Andalucia (southern Spain). The selection of the farms was based upon a previous study, which included a history of high prevalence of mastitis in the herds $(>15 \%)$, the onset of nutritional myodystrophy in goat kids, and the presence of low Se concentration in the soil of the farms (Andrés et al., 1997a).

Six hundred milking goats in their second or third lactation were selected according to the clinical state of the udder (i.e., absence of clinical signs of mastitis) and were randomly allotted to 2 groups. No therapy was applied at drying-off. The goats of the first group (treated group) received, $15 \mathrm{~d}$ before mating and conducted after heat synchronization, a subcutaneous injection of barium selenate at a dose of $1 \mathrm{mg}$ of Se/kg of BW (Zoselen LA, Laboratorios Esteve, Barcelona, Spain). The second group (control group) was not given any supplement containing this trace element. The subsequent pregnancy diagnosis, performed by echography, permitted the selection of 260 does in each group (Table 1).

All goats were under the same husbandry and nutrition practices through the trial. During the last third of gestation and the lactation, hay harvested in the same farm was offered ad libitum, and $250 \mathrm{~g}$ of concentrate of local source, a mixture of barley, corn, and beans, was given in the milking parlor. Supplemental Se was not fed.

Kids were separated from their mothers $72 \mathrm{~h}$ after birth and nursed with a milk replacer. The goats were milked twice a day using a milking machine. During lactation, the does were monitored at weekly intervals to assess the occurrence of clinical mastitis. A physical examination was performed for evidence of mammary gland inflammation (redness, heat, swelling, or pain). After looking for grossly abnormal changes in the milk, a California Mastitis Test (CMT; Bovi-Vet, Kruuse, Germany) was conducted. According to the recommendations of Contreras et al. (1996) and Perrin et al. (1997), the CMT was considered indicative of presumed IMI when a score 2 (evidence of gel) or score 3 (gel adhered to the bottom of the cup) was detected. A clinical case of mastitis was defined by the presence of clini- cal signs suggestive of mammary gland inflammation and score 2 or 3 for CMT. When a doe was found to be positive for clinical mastitis the animal was removed from the experiment and received the proper therapy.

\section{Samples}

Blood samples were taken by jugular venipuncture from all the animals in the trial immediately before treatment with barium selenate and at kidding. Samples were refrigerated and put into heparinized tubes (Venoject, Becton Dickinson, Madrid, Spain) until analysis $24 \mathrm{~h}$ later.

At 25,100 , and $200 \mathrm{DIM}, 20 \mathrm{~mL}$ of milk was collected from each goat without clinical mastitis before the morning milking. Azidiol ( $0.024 \mathrm{~g}$ of sodium azide/100 $\mathrm{mL}$; Sigma-Aldrich, Madrid, Spain) was added as a preservative. In those goats positive for clinical mastitis in any of the weekly examinations, $10 \mathrm{~mL}$ of milk from each infected udder half was obtained aseptically in sterile vials for bacteriological study. All milk samples were cooled at $4^{\circ} \mathrm{C}$ and immediately sent to the laboratory (Laboratorio Agroalimentario de Extremadura, Cáceres, Spain). Analysis was performed within $24 \mathrm{~h}$.

Together with the milk samples, hay and concentrate samples were randomly taken from the feed bunks and milking parlor, placed in transparent plastic bags, and maintained at room temperature until analysis. The $\mathrm{Se}$ content in the ration was measured by graphite furnace atomic absorption spectrometry after standard extraction procedures (550 SE, Perkin Elmer, Wellesley, MA).

\section{Erythrocyte GSHpx Activity}

Erythrocyte GSHpx activity was determined spectrophotometrically (UV160A, Shimazdu, Kyoto, Japan) on heparinized whole blood using a commercial kit (Ransel, Randox, Crumlin, UK). The final results of GSHpx activity were reported in units per gram of hemoglobin (IU/g of Hb). Hemoglobin was determined with an automated cell counter (Syxmex F-900, Roche, Barcelona, Spain).

\section{SCC}

Somatic cell counts were obtained by flow cytometry (Fossomatic 250, Foss Electric, Hillerød, Denmark).

\section{Milk Composition}

A Fourier transformation infrared spectrometer was used to explore the medium infrared spectrum in milk samples; the contents of fat, lactose, and protein were quantified after the proper calibration process (Milkoscan, Foss Electric). 
Table 2. Blood glutathione peroxidase activities (mean \pm SE; IU/g of $\mathrm{Hb}^{1}$ ) in the treated and the control groups in the 2 samplings

\begin{tabular}{lccccc}
\hline & \multicolumn{2}{c}{ Treated } & & \multicolumn{2}{c}{ Control } \\
\cline { 2 - 3 } \cline { 5 - 6 } Farm & 1st sample & 2nd sample & & 1st sample & 2nd sample \\
\hline AT & $32 \pm 1.5$ & $259 \pm 3.9^{\mathrm{a}}$ & & $40 \pm 2.3$ & $38 \pm 2.0$ \\
EC & $41 \pm 2.2$ & $318 \pm 4.0^{\mathrm{a}}$ & & $45 \pm 1.4$ & $43 \pm 1.3$ \\
PM & $35 \pm 1.9$ & $252 \pm 2.4^{\mathrm{a}}$ & & $33 \pm 1.3$ & $34 \pm 1.5$ \\
SA & $62 \pm 2.0$ & $497 \pm 7.4^{\mathrm{a}}$ & & $60 \pm 1.9$ & $58 \pm 1.6$ \\
Total & $43 \pm 1.0$ & $334 \pm 2.2^{\mathrm{a}}$ & & $45 \pm 0.8$ & $43 \pm 0.9$ \\
\hline
\end{tabular}

${ }^{\text {a }}$ Means within a row with different superscripts $\operatorname{differ}(P<0.001)$.

${ }^{1}$ International units per gram of hemoglobin.

\section{Microbiological Analysis}

From each sample, $10 \mu \mathrm{L}$ was spread onto the surface of a blood agar plate with $5 \%$ washed sheep erythrocytes and Saboureaud medium. Plates were incubated aerobically at $37^{\circ} \mathrm{C}$ and examined after 24,48 , and $72 \mathrm{~h}$. An IMI was diagnosed when 5 or more identical colonies were isolated from a milk sample. Duplicate plates were made to ensure that the same pathogen was isolated on all plates.

\section{Statistical Analysis}

A $\chi^{2}$ distribution test on $2 \times 2$ contingency tables was performed to explore the association between the occurrence of clinical mastitis and Se treatment. The logarithm SCC was used to normalize distribution of SCC. Normally distributed data were studied by repeated-measures ANOVA using a split-plot design with Se treatment as a between-subject factor and time as a within-subjects factor. This test was selected to check the differences between the mean activities of GSHpx, SCC, and the mean concentrations of fat, lactose, and protein in the control and treated groups throughout the time of the experiment. The SPSS 12.0 statistical package (SPSS Inc., Chicago, IL) was used (Pérez, 2001).

\section{RESULTS}

The average Se concentration (mean $\pm \mathrm{SE}$ ) was 0.027 $\pm 0.004 \mathrm{mg} / \mathrm{kg}$ in hay and $0.040 \pm 0.006 \mathrm{mg} / \mathrm{kg}$ in the concentrate.

Activity of GSHpx (IU/g of Hb) is given in Table 2 . The mean global activity ( $\pm \mathrm{SE}$ ) in the treated group was $43 \pm 1.0 \mathrm{IU} / \mathrm{g}$ of $\mathrm{Hb}$ before treatment, and $334 \pm$ $2.2 \mathrm{IU} / \mathrm{g}$ of $\mathrm{Hb}$ after treatment. In the control group, a mean activity of $45 \pm 0.8 \mathrm{IU} / \mathrm{g}$ of $\mathrm{Hb}$ was recorded in the first sampling and $43 \pm 0.9 \mathrm{IU} / \mathrm{g}$ of $\mathrm{Hb}$ in the second one. There were significant differences $(P<0.001)$ between the control and the treated groups only in the second sampling (i.e., after treatment).
Table 3 shows the geometric mean (log 10) SCC in the milk samples obtained at the beginning, middle, and end of the lactation. The ANOVA performed revealed significant differences between the treated and control groups.

Table 4 shows the number of cases of clinical mastitis in each farm and in total, together with values for $\chi^{2}$ and the level of significance of the comparison between the treated group and the control group. Significant differences were detected for the occurrence of mastitis in each farm and globally.

The bacteria most frequently isolated in the udder of the goats with clinical mastitis were CNS, followed by gram-negative bacilli and corynebacteria.

The mean content $( \pm \mathrm{SE})$ of fat in the milk ranged from $6.0 \pm 0.06 \%$ to $6.4 \pm 0.09 \%$. The content of lactose recorded was between $4.0 \pm 0.01 \%$ and $4.7 \pm 0.04 \%$. Finally, the maximum content of protein obtained in the milk was $3.4 \pm 0.03 \%$ and the minimum $3.1 \pm 0.01 \%$. The statistical appraisal of these data showed an absence of significant differences between the control and treated groups and throughout the lactation.

\section{DISCUSSION}

The concentration of Se found in the pastures and concentrates consumed by the animals in our experiment did not meet the Se requirements for dairy goats (Rankins et al., 2002). This may be explained because the experiment was conducted in a Se-deficient area, where Se-responsive diseases are enzootic. This problem is related to the acidic $\mathrm{pH}$ and the high content of sulfates and phosphorus in the soil (Andrés et al., 1997a); these elements inhibit the absorption of Se. Pastures and crops from these areas are poor in Se, and so is the diet of the animals fed on them.

The presence of Se deficiency in this area was confirmed by the low values of GSHpx activity obtained in the 2 groups of animals before treatment. These values may be considered deficient (Andrés et al., 1999) and they were the result of the poor ration received by the does before the last third of gestation. Before Se administration, there were no significant differences between the control and treated groups, because both groups received the same ration. As expected, the values in the control group did not change very much, whereas the activity of the enzyme increased 8-fold in the treated group (Table 2). This increase in GSHpx activity was similar to that obtained using the same Se source in ewes, by Van Ryssen et al. (1992) in South Africa, and Andrés et al. (1997b) in the same geographical area in which the current trial was conducted.

In healthy cows most of the cells found in the milk are macrophages, whereas in dairy goats, neutrophils 
Table 3. Geometric mean (log) milk SCC (mean \pm SE) in the nonmastitic goats of the treated and the control groups in the 3 samplings during lactation (at 25, 100, and 200 DIM)

\begin{tabular}{llcccccc}
\hline & \multicolumn{3}{c}{ Treated } & & \multicolumn{3}{c}{ Control } \\
\cline { 2 - 3 } Farm & 25 DIM & 100 DIM & 200 DIM & & 25 DIM & 100 DIM & 200 DIM \\
\hline AT & $5.2 \pm 0.6^{\mathrm{a}}$ & $5.1 \pm 0.6^{\mathrm{a}}$ & $5.7 \pm 0.5$ & & $5.9 \pm 0.7$ & $5.8 \pm 0.7$ & $6.1 \pm 0.7$ \\
EC & $5.8 \pm 0.5$ & $5.7 \pm 0.6$ & $6.0 \pm 0.6$ & & $5.9 \pm 0.6$ & $6.0 \pm 0.6$ & $6.1 \pm 0.6$ \\
PM & $5.1 \pm 0.6^{\mathrm{a}}$ & $5.3 \pm 0.5^{\mathrm{a}}$ & $5.7 \pm 0.7$ & & $5.7 \pm 0.7$ & $5.6 \pm 0.7$ & $5.8 \pm 0.7$ \\
SA & $5.2 \pm 0.6^{\mathrm{a}}$ & $5.1 \pm 0.6^{\mathrm{a}}$ & $5.3 \pm 0.6^{\mathrm{a}}$ & & $5.7 \pm 0.7$ & $5.7 \pm 0.7$ & $5.9 \pm 0.7$ \\
Total & $5.4 \pm 0.3^{\mathrm{a}}$ & $5.4 \pm 0.3^{\mathrm{a}}$ & $5.7 \pm 0.3^{\mathrm{ab}}$ & & $5.8 \pm 0.3^{\mathrm{b}}$ & $5.8 \pm 0.3^{\mathrm{b}}$ & $6.0 \pm 0.3^{\mathrm{b}}$ \\
\hline
\end{tabular}

${ }^{\mathrm{a}, \mathrm{b}}$ Means within a row with different superscripts differ $(P<0.05)$.

are the main cellular component, both in healthy and infected glands (Contreras et al. 1997). Phagocytosis of bacteria by polymorphonuclear neutrophils (PMN) are the principal line of defense against IMI (Paape et al., 2004). High SCC has been related to the presence of IMI in dairy goats. According to Perrin et al. (1997), SCC $>750,000$ cells/mL may be suggestive of IMI, although Contreras et al. (1996) recorded SCC of $1,115,000$ cells $/ \mathrm{mL}$ in goats with noninfected udders. The high SCC found in infected glands, together with the positive effect of Se on the activity of neutrophils, gave importance to the use of Se to diminish SCC indirectly, through the improvement of PMN function (Hogan et al., 1989).

The SCC in the milk of the goats in the control group of our experiment (Table 3) was within normal limits; that is, considered normal for a noninfected udder (Contreras et al., 1996; Poutrel et al., 1997). These low values may be due to the good state of udder health in the animals of this group.

In contrast to the findings of Lacetera et al. (1999), who did not detect any effect of Se on SCC, the SCC in the milk samples of the treated goats in our experiment was significantly lower in 3 of the 4 farms at 25 and 100 DIM (Table 3). This effect was absent at 200 DIM, possibly because a long time had elapsed since Se administration. The positive action of Se on the activity

Table 4. Number of cases of clinical mastitis in each farm, and in total, and results of the statistical comparison between the treated and the control groups

\begin{tabular}{lccccc}
\hline Farm and status & Treated, n & Control, n & $\chi^{2}$ & $P$-value \\
\hline AT & Mastitis + & 2 & 10 & 5.9259 & $<0.05$ \\
& Mastitis - & 58 & 50 & & \\
EC & Mastitis + & 3 & 11 & 5.0420 & $<0.05$ \\
& Mastitis - & 72 & 64 & & \\
\multirow{2}{*}{ PM } & Mastitis + & 2 & 9 & 4.9041 & $<0.05$ \\
& Mastitis - & 58 & 51 & & \\
\multirow{5}{*}{ Total } & Mastitis + & 3 & 10 & 4.1880 & $<0.05$ \\
& Mastitis - & 62 & 55 & & \\
& Mastitis + & 10 & 40 & 19.914 & $<0.001$ \\
& Mastitis - & 250 & 220 & & \\
\hline
\end{tabular}

of the immune system, protecting neutrophils against oxidative damage, supports this finding. There is an increase in the function and survival of these cells (Paape and Capuco, 1997), and thus, the migration of PMN into the udder is lower.

As in our experiment, Atroshi et al. (1985) and Morgante et al. (1999) conducted experiments in, respectively, goats and sheep deficient in Se and observed a positive effect of this trace element on SCC. In the experiment of Morgante et al. (1999), who performed differential counts, the ewes treated with Se showed lower SCC than the untreated ewes, due to fewer eosinophils and neutrophils in the milk of the animals that received the treatment.

The evolution of SCC throughout lactation in the 2 groups of our experiment showed an association between milk production and the number of cells, with increments of SCC at the end of lactation. This increase may be the result of the decrease in milk production and a subsequent concentration effect (Wilson et al., 1995).

Some studies indicate that Se reduces the incidence and the duration of clinical mastitis (Smith et al., 1984). This action may be a consequence of an improvement in the function of neutrophils in the udder, because it has been reported that PMN of Se-deficient cows contain a large quantity of hydrogen peroxide and these cells are less viable and less capable of scavenging bacteria (Smith et al., 1997).

Erskine et al. (1987) reported a negative correlation between the percentage of quarters infected in dairy cows and mean herd GSHpx activity in whole blood. Atroshi et al. (1985) found that mastitic dairy goats had lower erythrocyte GSHpx than healthy goats, and Weiss et al. (1990) reported reduced rates of clinical mastitis associated with high serum Se concentrations. Morgante et al. (1999) indicated a similar trend, and our results confirm this hypothesis, because significant differences in the incidence of mastitis between the control and treated groups were recorded (Table 4). This difference might be explained by the inhibitory effect of GSHPx on bacterial growth in cow's milk reported by Malbe et al. (2006). 
The microbiota implied in the production of clinical mastitis in our trial was the usual flora related to IMI in dairy goats under the same husbandry practices in Mediterranean areas (Contreras et al., 1997).

Finally, no significant differences were found for milk composition between the control and the treated groups. These results differ from the findings of different researchers (Duranti and Casoli, 1991; Sánchez et al., 2002) who recorded differences in the content of lactose, fat, and protein between milk samples with high and low SCC. The difference between our results and those obtained previously may be explained because they obtained SCC indicative of severe inflammation of the mammary gland, whereas in our case, the samples from mastitic goats were discarded.

\section{CONCLUSIONS}

The administration of barium selenate to goats before mating had beneficial effects during the subsequent lactation. The effects included reduction of SCC and reduction in the incidence of clinical mastitis. However, no effect on milk composition was recorded. Thus, in Se-deficient areas, the use of supplemental Se, including slow-release Se sources such as barium selenate, could be recommended to reduce SCC and prevent clinical mastitis.

\section{ACKNOWLEDGMENTS}

The authors acknowledge the support of Junta de Extremadura and Fondo Social Europeo (PRI97D036) in the funding of this study. The authors also acknowledge the valuable technical assistance of Laboratorio Agrario de Extremadura (Junta de Extremadura).

\section{REFERENCES}

Andrés, S., A. Jiménez, M. C. Mañé, J. Sánchez, and R. Barrera. 1997a. Relation between some soil parameters and the blood glutathione peroxidase activity of grazing sheep. Vet. Rec. 141:267-268.

Andrés, S., M. C. Mañé, J. Sánchez, R. Barrera, and A. Jiménez. 1999. Temporal variations in blood glutathione peroxidase (GSHPx) activity in sheep at pasture in a Mediterranean area. Vet. J. 157:186-188.

Andrés, S., M. C. Mañé, J. Sánchez, R. Barrera, C. Zaragoza, and A. Jiménez. 1997b. Response to barium selenate supplementation in sheep kept at pasture in the Mediterranean area. Vet. Res. 28:539-545.

Atroshi, F., S. Sankari, and U. B. Lindstrøm. 1985. Glutathione peroxidase activity in dairy goat erythrocytes in relation to somatic cell counts and milk production. Arch. Exp. Vet. Med. 39:520-524.

Contreras, A., J. C. Corrales, A. Sánchez, and D. Sierra. 1997. Persistence of subclinical intramammary pathogens in goats throughout lactation. J. Dairy Sci. 80:2815-2819.

Contreras, A., D. Sierra, J. C. Corrales, A. Sánchez, and J. Marco. 1996. Physiological threshold of somatic cell count and California
Mastitis Test for diagnosis of caprine subclinical mastitis. Small Rumin. Res. 21:259-264.

Duranti, E., and C. Casoli. 1991. Variazione della composizione azotata e dei parametri lattodinamografici del latte di pecora in funzione del contenuto di séllele somatiche. Zootec. Nutr. Anim. 18:99-105.

Erskine, R. J., P. L. Eberhart, L. J. Hutchinson, and R. W. Scholz. 1987. Blood selenium concentrations and glutathione peroxidase activities in dairy herds with high and low somatic cell counts. J. Am. Vet. Med. Assoc. 190:1417-1423.

Hogan, J. S., K. L. Smith, P. S. Hoblet, D. A. Schoenberger, W. D. Todhunter, D. E. Hueston, G. L. Pritchard, L. Bowman, B. L. Heider, B. L. Brockett, and H. R. Conrad. 1989. Field survey of mastitis in low somatic cell count herds. J. Dairy Sci. 72:15471552.

Lacetera, N., U. Bernabucci, B. Ronchi, and A. Nardone. 1999. The effects of injectable sodium selenite on immune function and milk production in Sarda sheep receiving adequate dietary selenium. Vet. Res. 30:363-370.

Malbe, M., M. Attila, and F. Atroshi. 2006. Possible involvement of selenium in Staphylococcus aureus inhibition in cow's whey. J. Anim. Physiol. Anim. Nutr. (Berl.) 90:159-164.

Matthews, J. 1999. Diseases of the Goat. 2nd ed. Blackwell, Oxford, UK.

Miller, J. K., E. Brzezinska-Slebodzinska, and F. C. Madsen. 1993. Oxidative stress, antioxidants, and animal function. J. Dairy Sci. 76:2812-2823.

Morgante, M., D. Beghelli, M. Pauselli, P. Dall'Ara, M. Capuccella, and S. Ranucci. 1999. Effect of vitamin $\mathrm{E}$ and selenium during the dry period on mammary health and milk cell counts of ewes. J. Dairy Sci. 82:623-631.

Paape, M. J., and A. V. Capuco. 1997. Cellular defense mechanisms in the udder and lactation of goats. J. Anim. Sci. 75:556-565.

Paape, M. J., A. Contreras, and T. K. Ledbetter. 2004. Variation among goats in the ability of their polymorphonuclear neutrophil leukocytes and mammary secretions to support phagocytosis: Inhibitory effects of milk fat globules. Small Rumin. Res. 54:183189.

Pérez, C. 2001. Técnicas estadísticas con SPSS. Pearson Educación, Madrid, Spain.

Perrin, G. G., M. P. Mallereau, D. Lenfant, and C. Baudry. 1997. Relationships between California mastitis test (CMT) and somatic cell counts in dairy goats. Small Rumin. Res. 26:167-170.

Poutrel, B., R. de Cremoux, M. Ducelliez, and D. Verneau. 1997. Control of intramammary infections in goats: Impact on somatic cell counts. J. Anim. Sci. 1997:566-570.

Rankins, D. L., D. C. Ruffin, and D. G. Pugh. 2002. Feeding and nutrition. Pages 19-60 in Sheep and Goat Medicine. D. G. Pugh, ed. W.B. Saunders Company, Philadelphia, PA.

Sánchez, A., C. Fernández, A. Contreras, C. Luengo, and J. Rubert. 2002. Effect of intramammary infection by Staphylococcus caprae on somatic cell counts and milk composition in goats. J. Dairy Res. 69:325-328.

Smith, K. L., J. H. Harrison, D. D. Hancock, D. A. Todhunter, and H. R. Conrad. 1984. Effect of vitamin E and selenium supplementation on incidence of clinical mastitis and duration of clinical symptoms. J. Dairy Sci. 67:1293-1300.

Smith, K. L., J. S. Hogan, and W. P. Weiss. 1997. Dietary vitamin $\mathrm{E}$ and selenium affect mastitis and milk quality. J. Anim. Sci. 75:1659-1665.

Van Ryssen, J., G. D. Bradfield, S. Van Malsen, and J. F. Devilliers. 1992. Response to selenium supplementation of sheep grazing cultivated pastures in the Natal Midlands. J. S. Afr. Vet. Assoc. 4:148-155.

Weiss, W. P., J. S. Hogan, K. L. Smith, and K. H. Hoblet. 1990. Relationships among selenium, vitamin $\mathrm{E}$, and mammary gland health in commercial dairy herds. J. Dairy Sci. 73:381-387.

Wilson, D. J., K. N. Stewart, and P. M. Sears. 1995. Effects of stage of lactation, production, parity and season on somatic cell counts in infected and uninfected dairy goats. Small Rumin. Res. $16: 165-169$ 